\title{
Small-scale innovations in coastal communities: shell-handicraft as a way to empower women and decrease poverty
}

\author{
$\underline{\text { Sara Fröcklin }}^{1}$, Narriman S. Jiddawi $^{2}$ and Maricela de la Torre-Castro ${ }^{3}$
}

\begin{abstract}
We analyzed the potential of small-scale innovations, such as shell-handicraft, as a way to foster transformation toward sustainability, decrease poverty, and increase women's empowerment in Zanzibar, Tanzania. The shell-handicraft project was founded by USAID in 2006 and was introduced as an alternative livelihood to low-paid seaweed farming and invertebrate harvesting activities. The main objective, however, was to not only alleviate poverty and empower women, but also to improve management of coastal resources, and allegedly by doing so, break poverty traps. To analyze the potential benefits of this enterprise, and more specifically whether or not women involved in this project have been empowered, a framework was used that comprises three inter-related dimensions; agency, access to resources, and outcome. Agency includes the process of decision making, negotiation, etc., in which choices are made and put into effect. Access to resources (financial, physical, human, and social) is the medium through which agency is exercised, and outcome can be defined as the result of agency. Simply put, resources and agency make up people's potential for living the lives they want. Semistructured interviews were administered to a group of women $(n=36)$ involved in shell-handicraft and a group of women not involved in shell-handicraft $(n=36)$ in five villages located in central/south Zanzibar. The results show that over time, the women engaged in shell-handicraft have improved their access to a range of resources, mainly physical (house, cell phone, freezer, and electricity), human (knowledge in marketing, leadership, and entrepreneurship), and social (organization). This further resulted in reported improved self-confidence and decision-making authority within the household. Regarding financial resources, both savings and income improved for the targeted group, but more research is advised. Positively, the environmental impacts of the activity are seemingly low. Old shells are collected for handicraft and a number of no-take zones, as part of the project, have been established to preserve marine resources, which allowed for women's participation in coastal management. The project has also empowered women and challenged stereotypes, aspects critical for progressive and inclusive management. Although all in all, the women interviewed were satisfied and had increased their standard of living, the discussion problematizes this innovation by addressing scaling up possibilities, market constraints, and the kick-off process having external top-down elements. Even though the recipients of the benefits from the project have been few, this case has valuable elements to learn from and can provide inspiration to drive coastal systems into more sustainable paths.
\end{abstract}

Key Words: coastal livelihoods; empowerment; poverty; resilience; transformations; Zanzibar

\section{INTRODUCTION}

As the biosphere of the planet becomes degraded, a search for solutions and creative proposals to build sustainable natural resource use and human well-being is taking place globally (e.g., Seeds of Good Anthropocene, https://goodanthropocenes.net). In the coastal/marine realm, declining fisheries, degraded ecosystems, and widespread poverty are common in many tropical countries throughout the world. The island of Zanzibar (Unguja, Tanzania, East Africa) is no exception. Being an island, most people are highly dependent on marine resources. However, traditional coastal livelihoods are becoming threatened. For example, studies have shown that fish and invertebrate resources are declining (Jiddawi and Öhman 2002, Eriksson et al. 2010, Nordlund et al. 2010, Fröcklin et al. 2014), and the more recently introduced seaweed mariculture of Euchemoids may negatively affect surrounding seagrass ecosystems and associated fauna (e.g., Eklöf et al. 2006) and women farmers' health because of poor working conditions (Fröcklin et al. 2012). The coastal tourism industry has grown enormously during the last decades, but research is scarce and it is questionable if the local population really benefits from the industry (Lange 2015). In addition, coastal activities are shaped by gender inequality and women normally have less access to financial, physical, human, and social resources as well as decisionmaking authority (Fröcklin et al. 2013). Further, there is a lack of attention given to women's roles as daily resource users, as well as gender mainstreaming in policy, management, and governance. Control and participation regarding marine resources are particularly uneven as a result of unequal distribution of power (Fröcklin 2014, de la Torre-Castro et al. 2017). Traditional stereotypes of women's capabilities and gender structures in society have been identified as a hindrance (de la Torre-Castro et al. 2017). This makes women particularly vulnerable to declining coastal/marine resources and thus susceptible to social-ecological poverty traps (see Haider 2017, for a nuanced discussion on traps). Subsequently, the need for alternative solutions and paths for a better future is urgent.

In this context, shell-handicraft was introduced in Zanzibar as an innovation with multiple objectives: (a) to empower women, (b) to increase economic standards, and (c) to stop unsustainable exploitation of invertebrates. The SUCCESS project (Sustainable Coastal Communities and Ecosystems) founded by USAID started in 2006, as a result of a joint collaboration between the Institute of Marine Science (IMS) and the Western Indian Ocean Marine Science Association (WIOMSA), as well as the University of Hawaii and University of Rhode Island (Coastal Resource Centre, CRC, http://www.crc.uri.edu/activities_page/backgroundon-the-pearl-project/). The project targeted women's groups that were previously engaged in low-income generating activities, e.g., seaweed farming, agriculture/forestry/husbandry, and invertebrate harvesting. It further intended to expose women to the enterprise

${ }^{1}$ Department of Ecology, Environment and Plant Sciences, Stockholm University, Stockholm, Sweden, ${ }^{2}$ Institute of Marine Science, University of Dar es Salaam, Zanzibar, Tanzania, ${ }^{3}$ Department of Physical Geography, Stockholm University, Stockholm, Sweden 
itself plus a set of other benefits such as forming organizations and providing training in marketing and entrepreneur skills, as well as increasing their participation in decision-making processes, with the objective of challenging traditional gender roles.

Over the last years, women's empowerment linked to the marine environment and particularly fisheries has gained more focus, both in research (see, e.g., Fröcklin 2014 and references therein) and in international policy, e.g., the FAO's Voluntary Guidelines for Securing Sustainable Small-Scale Fisheries in the Context of Food Security and Poverty Eradication, the first instrument dedicated entirely to small-scale fisheries and building on human rights and gender equality (http://www.fao.org/3/a-i4487e.pdf). However, to our knowledge there is no scientific analysis dealing with women's empowerment and the broader ideas of linking innovation, management, and transformation in a marine context. To analyze the potential of such small-scale innovations, this research builds on a social-ecological system (SES) approach combined with the empowerment literature. Specifically, three main areas are considered: precondition, agency, and outcome following Kabeer's $(1995,1999)$ ideas and typology of women's empowerment. To further analyze the process of innovation and management we used SES resilience-based management as proposed in Olsson et al. (2006). Particularly we focus on the following: (a) preparing the system to change, e.g., how the enterprise was introduced, (b) navigating the transition, e.g., changes from the initial states to tangible outcomes, and (c) building resilience of the new governance regime, e.g., how external actors exit and what are the obstacles and possibilities for the future. Finally, the scale of the enterprise as well as the market and management challenges are discussed as well.

\section{Empowerment}

We draw our work on Kabeer's (1999:435) framework on women's empowerment in which "those who have been denied the ability to make strategic life choices acquire such ability." This process includes three inter-related dimensions; agency, which refers to the process of decision making, negotiation, deception, and manipulation and in which choices are made and put into effect; access to resources (financial, physical, human, and social), which is the precondition for choice; and outcome, simply defined as the result of agency. However, studies have shown that improved access to resources may not necessarily mean that an individual possesses the ability to make strategic life choices (Kabeer 2005). Inadequate institutional designs, cultural norms, gender inequalities, and unbalanced power dynamics can still constrain people's ability to make strategic choices and act upon them. Previous studies from Zanzibar (see, e.g., Fröcklin 2014, de la Torre-Castro et al. 2017) have shown that gender inequalities and power imbalances are typical features both at household, community, and political levels. Seemingly, measuring the process of empowerment is far from simple and should be viewed as highly contextual and multidimensional (Kabeer 1999). We make an attempt to capture women's empowerment by analyzing the situation prior to the introduction of shell-handicraft (preconditions in access to resources and decision-making authority), and the situation seven years later (outcome in access to resources and decision-making authority). We then discuss SES transformation and resilience to bring into focus how small-scale innovations can target particular dimensions of empowerment to foster transformative capacities in order to effectively participate in decision-making processes. Finally, we elaborate on the potential of such transformations to translate into socialecological resilience, i.e., "the capacity to adapt or transform in the face of change in social-ecological systems, particularly unexpected change, in ways that continue to support human wellbeing" (Folke et al. 2016).

\section{METHODS}

\section{Study sites}

The study used participant observations and semistructured interviews to collect quantitative and qualitative data (Kvale 1994, Denscombe 2007). Gathering these types of data enabled the authors of this paper to triangulate the information obtained. The research was carried out in five villages (Bweleo, Bondeni, Chaleni, Kizingo, and Nyamanzi) on Unguja Island (hereafter referred to as Zanzibar) during August to September 2013 (Fig. 1). Zanzibar is a semiautonomous part of the United Republic of Tanzania and is made up of several islands, Unguja being the largest with approximately 1,300,000 inhabitants (World Population Review 2018). The five studied villages are, together with an additional three, the only sites in Zanzibar where shellhandicraft, as part of the SUCCESS project, takes place. The approximate current number of women shell-handicrafters, throughout the eight villages, is 240 (IMS 2018, personal communication). The reason for not including all eight villages was time constraints and a limited budget. However, the sites selected were considered to be representative as discussed with local scientists affiliated to the IMS.

Fig. 1. Study area of Zanzibar (Unguja), Tanzania: $06^{\circ} 08^{\prime} 00^{\prime \prime} \mathrm{S}$, $39^{\circ} 19^{\prime} 00^{\prime \prime}$ E. Sampled villages $(n=5)$ are found within the dotted square except Kizingo, which is located east of Zanzibar Town.

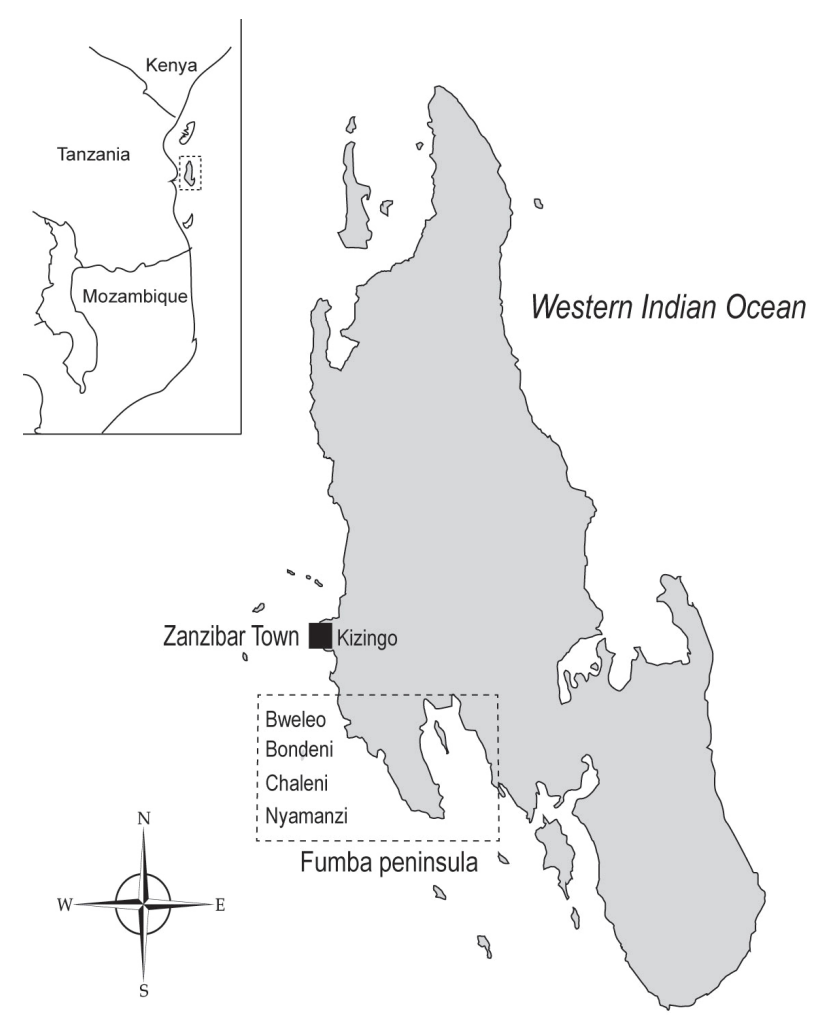


Similar to most villages in Zanzibar, the main livelihoods in the investigated villages include fishing, seaweed farming, and invertebrate harvesting from near-shore shallow areas. The latter is an important activity specifically for women, and about 1000 persons (mostly women and children) in almost every household in the Fumba peninsula are involved in this activity (Crawford et al. 2010). This number has been steadily increasing, partly as a result of commercialization of cockles that are easy marketed in Zanzibar town, posing threats to the sustainability of resource stocks and thus people's livelihoods (Crawford et al. 2010).

\section{Interviews}

To capture preconditions and outcomes during a seven year time period (the project's introduction in 2006 to the time of the study), semistructured interviews were administered to women involved in shell-handicraft $(\mathrm{n}=36)$, as well as a control group consisting of women engaged in other activities such as seaweed farming, petty business, cutting firewood, gleaning, or teaching $(n=36)$. The focus was to capture potential changes in access to financial, physical, human, and social resources, decision making in the household, and self-confidence. As mentioned previously, Kabeer's (1999, 2005) dimension of "resources" was applied and a set of measurable categories based on the authors' previous work in the field were developed. In addition, background information such as household structure and education as well as questions related to market, challenges, and future prospects were included. The shell-handicraft respondents were selected based on the criteria that they should be involved in this enterprise as their main livelihood. Verbal consent from participants was obtained prior to all interviews. The participants were informed about the purpose of the study and how the data would be utilized as well as anonymity. Only those giving consent were interviewed. The interviews were performed by the first author and with assistance from an interpreter at IMS, who simultaneously translated between English and Kiswahili. All interviews were recorded using a Dictaphone for further analysis. The interviews generally lasted one hour and took place in the village, usually in the respondent's home. In addition, observations of daily village activities, the production of shell-handicraft, and at selling spots took place.

\section{Statistical analysis}

The answers provided on access to physical, human, and social resources, as well as decision-making authority, were transcribed and coded into answer groups $(1=$ positive and $0=$ negative $)$ to perform further analysis. A symmetry test was then used to test for differences in precondition and outcome of access to physical, human, and social resources within the two groups (shellhandicraft and control group). Significant levels were considered at $\mathrm{P}<0.05$. Answers providing in-depth information were transcribed and analyzed by developing categories according to the statements and relevance for the study, e.g., general work situation and challenges. The statistical analyses were performed using the Stata (version 11) program.

\section{RESULTS}

\section{Background of respondents}

The age of the women engaged in shell-handicraft varied from $18-56$ years, with most found in the range of $26-45$ years. The same age distribution was found within the control group. Almost one-third of the shell-handicrafters had no education $(27 \%)$ whereas two-thirds $(66 \%)$ had completed secondary school. Within the control group, $28(77 \%)$ out of 36 women had completed secondary school. More than two-thirds of the shellhandicrafters were married and had an average number of four children. Similar patterns were found in the control group. Few of the married women, including the control group, were heads of their respective households.

\section{Shell-handicraft}

Most of the women shell-handicrafters were introduced to this enterprise by the initiators of the joint SUCCESS project, or by women in their own village already engaged. They were further provided training in production, entrepreneurship skills, design, marketing, and business modelling as part of the project. In addition, the project included setting up a resource center in Fumba to facilitate exchange in knowledge and ideas by providing an organizational platform, as well as to assist in production and marketing of their products.

The main reason for introducing this alternative livelihood was to alleviate poverty and improve social and environmental conditions. Previously, women mainly gleaned shellfish for food. Thus, by introducing the farming of half-pearls (mabe) and production of shell-handicraft, the pressure on depleted shellfish stocks due to uncontrolled harvesting was assumed to decrease, while offering a new livelihood with the potential to boost the household economy for the women in southern Zanzibar. However, out of all women shell-handicrafters interviewed only four $(11 \%)$ of the 36 women were engaged in both shell-handicraft and the much more profitable activity of pearl farming. Farming pearls requires swimming-skills, which none of the women interviewed possessed. Thus, the few women involved in pearl farming were accompanied by their respective spouse and/or other male relative.

\section{... I would like to learn how to swim. If I knew how to swim, I could also engage in pearl farming and that's where the money is...today only men farm pearls... (Woman shell-handicrafter, age 33 in Kizingo village)}

The average number of years active in shell-handicraft was 6.2 ; however, more than half of the women respondents had been involved since its introduction in 2006 (a total of seven years). The most commonly sold products were earrings, bracelets, and necklaces, produced by shells collected by the women themselves in near-shore areas, or pearls (mabe) obtained from the men farmers. According to interviewed shell-handicrafters, it takes about two hours to manually grind and cut the shells into a piece of jewelry (Fig. 2). A majority (97\%) of the women then sold their products themselves, mostly to small shops, e.g., the resource center or shops in town. Based on observations at selling spots there are, in addition to the resource center in Fumba, about 10 shops in Zanzibar Town marketing the products. Twenty-eight $(78 \%)$ of the interviewed women also said that they sell their products to tourists through organized trips to nearby hotels, the neighboring Kwale island, and at festivals (e.g., Fair trade festival, Saba Saba festival, Zanzibar International Film Festival). The average price for the jewelry (across selling spots) varies from 3500 TZS (US\$1.5) for earrings to 10,000 TZS (US\$4.5) for necklaces and bracelets. Few variations in price among the various selling spots were found. 
Fig. 2. (A) Jewelry produced using farmed pearls (mabe in Kiswahili); (B) jewelry produced using collected sea shells (the earrings with a price tag) by local women in South Zanzibar, Tanzania.
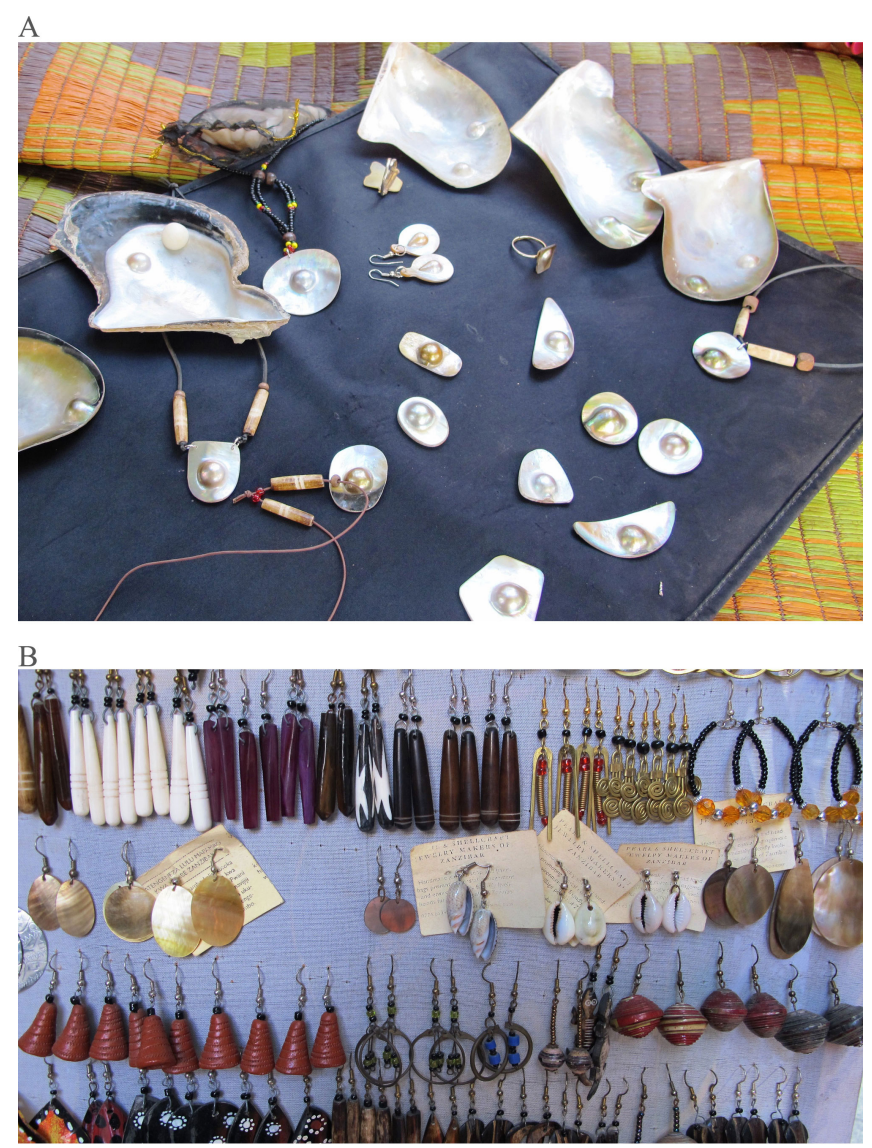

Financial, physical, human, and social resources: precondition and outcome

According to the results, the engagement in shell-handicraft has led to alleged life improvements in terms of access to financial, physical, human, and social resources (Fig. 3). Income wise, the average total daily income (combining all income generating activities) for shell-handicrafters increased from 4250 TZS (US\$1.9) to 6800 TZS (US\$3.1; 63\% increase). For the control group the average total daily income increased from 1006 TZS (US\$0.5) to 1733 TZS (US\$0.7; 58\% increase). The percentile increase between the two groups is not remarkably different; however, in net terms an increase in cash flow is a substantial gain in these coastal communities. Higher net income allows women to handle everyday expenses as well as to think about the future. Many of the women in the control group did not have a job seven years ago, which could partly explain the extremely low initial incomes, as well as the relatively high percentile increase. Another difference between the two groups is that all women shellhandicrafters have now been able to create their own savings account compared to none in the control group. It is difficult to assess if this is due to their engagement in shell-handicraft, or a combination of shell-handicraft and potential inflation in other income-generating products that they sell, e.g., seaweed, firewood, fish, and vegetables, given that income data is based on all livelihood activities. However, when asked about this, all women shell-handicrafters reported that their increased income and thus possibility to save money, is a direct result of this new enterprise, which the following quotes illustrate:

Fig. 3. Differences over time in access to physical, human, and social resources and self-confidence for women engaged in shell-handicraft $(n=36)$ and control group $(n=36)$.

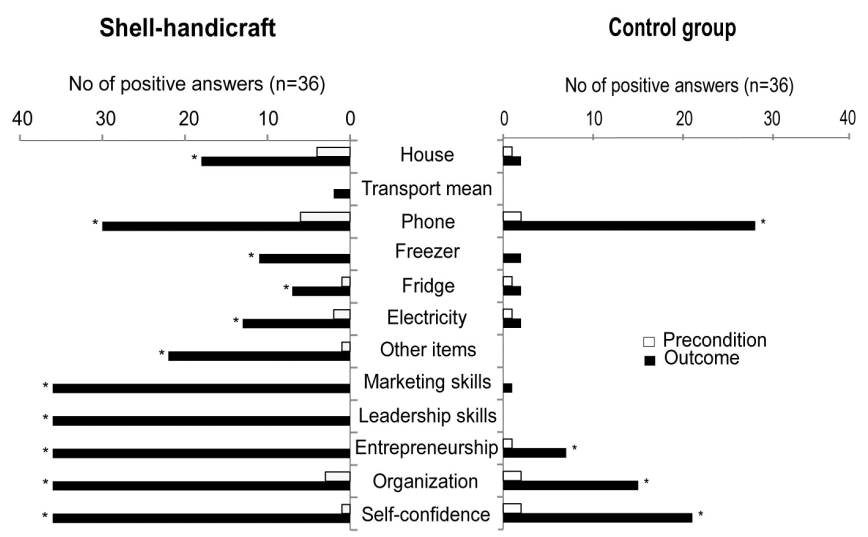

( ${ }^{*} \mathrm{p}<0.05$ indicates significant differences between precondition and outcome for respective group)

\begin{abstract}
...This is a very good business. Compared to my previous job (seaweed farming), which was very hard work and low-paid, I now earn a lot. Before I couldn't even afford a trip to town... (Woman shell-handicrafter, age 40 in Nyamanzi village)

... My goal is to build my own house. Look, I have already bought bricks for a new house. It is good to have your own house because you never know if your husband will stay with you or get another wife... (Woman shellhandicrafter, age 49 in Chaleni village)
\end{abstract}

An increase in income for women shell-handicrafters has further led to improved access to a set of other resources. For example, there was a significant difference in access to physical resources such as a house, mobile phone (average market price US\$16), freezer (average market price US\$99), refrigerator (average market price US\$110), and electricity $(\mathrm{P}<0.05)$. Almost all women shell-handicrafters now have acquired a mobile phone and half $(50 \%)$ have their own house or have started to build their own house. However, although buying a plot, if the women do not already have access (own or by inheritance) to land, is relatively cheap, building a house is much more expensive (average price for a house ranges between US\$10,000 to 15,000) and would thus require many years of saving. The statistical analysis showed significant differences for knowledge in marketing skills, leadership skills, entrepreneurship, and organization $(\mathrm{P}<0.05)$ where the number went from zero to $100 \%$ for the women engaged in shell-handicraft. These changes were not evident for the control group, where only changes in access to mobile phone, entrepreneurship, and organization were proven statistically significant over the given time frame (2006-2013). Less access to 
Table 1. Precondition and outcome in decision-making authority. Data based on interviews with women engaged in shell-handicraft $(\mathrm{n}=36)$ and control group $(\mathrm{n}=36)$. "Yes" indicates decision-making authority.

\begin{tabular}{|c|c|c|c|c|}
\hline \multirow[b]{2}{*}{ Decision-making authority } & \multicolumn{2}{|c|}{ Shell-handicrafters } & \multicolumn{2}{|c|}{ Control } \\
\hline & Precondition & Outcome & Precondition & Outcome \\
\hline Household purchases & 6 & 15 & 1 & 5 \\
\hline Clothing purchases & 9 & 18 & 3 & 4 \\
\hline Food purchases & 11 & 18 & 1 & 6 \\
\hline To work or not & 12 & 20 & 2 & 8 \\
\hline How to spend family's money & 3 & 10 & 1 & 4 \\
\hline How to spend own money & 20 & 31 & 21 & 27 \\
\hline Who to visit and when & 2 & 8 & 1 & 2 \\
\hline No. of children & 4 & 12 & 2 & 2 \\
\hline Children's schooling & 4 & 12 & 2 & 2 \\
\hline Children's marriage & 4 & 12 & 2 & 2 \\
\hline
\end{tabular}

physical resources is likely a result of their lower income. However, when it comes to improved self-confidence, both groups showed significant differences $(\mathrm{P}<0.05)$ before and after, yet, the number was higher for shell-handicrafters than for the control group (Fig. 3). According to both groups, improved self-confidence was very much linked to an increase in income and thus a sense of independence, which the following quotes illustrate:

\section{... Today (after engaging in shell-handicraft) I feel much more confident to speak up if I disagree (during community meetings) than before (when I was just shy and scared). People also think higher of me now when I earn my own money and have knowledge in how to design, produce, and market my own goods... (Woman shell- handicrafter, age 40 in Nyamanzi village) \\ ... Yes, I am much more confident. People respect me now when I have a job and earn my own income. I am a teacher.. (Woman teacher, age 54 in Bondeni village).}

Decision-making authority in the household: precondition and outcome

According to the interviewed shell-handicrafters, a large proportion $(69 \%)$ of their respective spouses has been very positive toward their engagement in this enterprise. This can largely be attributed to improved household economy. It is further clear that women's increase in income has somewhat shifted the decision-making structure in the household and 23 out of 36 women (64\%) experienced improved decision-making authority (Table 1). For some decisions, such as what to buy and eat, how many children to have, children's education and marriage, nearly half of the women shell-handicrafters considered themselves in charge. Overall, the shell-handicrafters interviewed perceived themselves much more influential in household decisions, as this quote illustrates: "Today we decide together, before he (my husband) decided everything..." (Woman shell-handicrafter, age 29 in Bondeni village).

A majority of the women shell-handicrafters (94\%) further stated that they now experienced greater agency, i.e., the ability to make strategic life choices and setting up goals to act upon. Examples given included opening a shop or building a house of their own. The number for the control group during the same time period was much lower (14\%). In general, the control group showed less change in decision-making authority at the household level and although they experienced some changes during the past seven years, many of them made similar statements: "My husband has the final say in all decisions..." (Woman farmer, age 31 in Bondeni village).

For both groups it was evident that decisions regarding where to go, who to visit, and when, are still to a large extent made by their respective spouses. Yet, there was a slightly higher improvement for women shell-handicrafters (from 2 to 8 ) and most of them said that as long as they ask for permission, they are usually permitted to travel.

\section{Challenges: the future of shell-handicraft}

Despite the women's optimistic attitudes toward shell-handicraft, and the relative positive impacts it has had on their lives, this enterprise is still paved with challenges. The quote below summarizes some of the main obstacles:

\section{... Tools and transport are problems. Also the market is too small. Mostly tourists buy our handicraft and there are fewer tourists today (than before). We would like to have better access to cheap handicraft tools as they break easily, and the opportunity to sell our items on a bigger market outside of Zanzibar. It would also be nice to have a small shop in town but I have no contacts there and I also need to take care of my children so time is limited... (Woman shell-handicrafter, age 32 in Bweleo village)}

Finding someone to repair broken equipment and polishing machines, and having the financial means to pay for the costs is a major challenge according to the interviewed women shellhandicrafters. Further, the women do not have their own machines, thus, they take turns on the few machines available (provided by the SUCCESS project) in the village. Subsequently, they are somewhat limited in how much they can produce. Moreover, production is not only limited by equipment deficiencies but also to time constraints due to unpaid household work and childcare. Increased production would require more time spent on shell-handicraft, as well as access to transport means and a more diverse market, something that is somewhat unavailable. Most women shell-handicrafters $(90 \%)$ expressed a wish to expand their market outside of Zanzibar. However, although all women shell-handicrafters stated that they have knowledge in market demand and a majority (75\%) had insight into "what is the best market," they generally lack contacts to 
diversify their markets beyond the Island. In addition, only 2 out of 36 women $(5 \%)$ indicated that they have access to their own transportation when needed. Related to market, there was further a general concern about seasonal fluctuations in tourism, and also about the potential increase in shell-handicrafters as more women get involved in this enterprise. Many of them feared that an upscaling would increase the competition over existing customers and further limit a market already limited to a few shops and tourists in Zanzibar only, illustrated by the following quote: "... The business would not be good if too many women joined..." (Woman shell-handicrafter, age 21 in Nyamanzi village)

Subsequently, limited and fluctuating markets have forced women shell-handicrafters $(97 \%)$, like most other women along Zanzibar's coast (e.g., Fröcklin 2014, de la Torre-Castro et al. 2017), to continue to engage in additional livelihoods such as keeping chickens, producing and selling local food, cutting firewood and charcoal, and other forms of petty business to make ends meet (for subsistence and income). However, all women interviewed answered that they like this new enterprise and that it has had an overall positive impact on their life situation.

\section{DISCUSSION}

\section{Has shell-handicraft led to women's empowerment?}

The study shows how the introduction of a new livelihood, shellhandicraft, has the potential to improve the situation for the selected group. In this case, access to financial, physical, human, and social resources increased for all women involved in the project. However, as mentioned in the results, income data is based on all income-generating activities and it is thus difficult to isolate shell-handicraft; other factors such as inflation, income from alternative livelihoods, or aggregated household income, can also play a role. Yet, to give an idea of average daily incomes for typical women-dominated activities in these coastal areas, reference can be made to the work done by de la Torre-Castro et al. (2017). Their analysis reveals that a woman fisher/gleaner earns on average US\$1.34/day, a woman involved in agriculture/forestry/ husbandry US\$1/day, a woman seaweed farmer US\$1.3/day, and a woman working in the tourism sector US\$1.95/day. Thus, the income generated from shell-handicraft (6800 TZS [US\$3.1]), although combined with above mentioned additional activities, is still higher than for the average coastal woman. This has likely, in combination with new knowledge and skills gained through training, played a critical role in their increased access to various forms of physical resources.

Further, all interviewed women reported that shell-handicraft has had positive effects on their individual, household, and social spheres of being, and thus to some degree strengthened household and potentially community resilience. Improved access to human (knowledge, skills) and social (networks, organization) resources as a result of the SUCCESS project has further likely contributed to greater agency and helped challenge decision-making structures at the household level, as well as boosting women's selfconfidence. At the individual level, women felt that their decisionmaking authority had increased at home; however other studies show that much of the power is still held by male counterparts (husband, father, older brother). Thus, it is unclear if improved decision-making authority at home automatically leads to an increase in decision-making overall, e.g., at the community level.
In addition, there are still decisions such as where to go, who to visit, and when, that are largely undertaken by men. Kabeer (2005) highlights that the last indicator of women's empowerment is how well they are represented in decision making taking place outside the household, i.e., community at large, or in the arena of politics. In the case of Zanzibar, previous studies (e.g., de la Torre-Castro et al. 2017) have shown that women are largely absent from such decision making and their roles, needs, and interests are commonly overlooked in Zanzibar's management system. There is further great incoherence between different decision-making authorities dealing with coastal management, gender, and community development. Although not the main objective of the SUCCESS project, there are still structures, e.g., institutional bias, cultural norms, gender inequalities, and unbalanced power dynamics, that must change in order for women to be able to fully make strategic life choices and act upon them. Nevertheless, the introduction of this enterprise has brought positive outcomes in a place where diversity of options, especially for women, is highly constrained. Thus, the project's objective to empower women, at least at individual and household levels, has to some degree been reached. Haider (2017) stresses the multidimensions of development interventions and poverty conceptualization. Subsequently, in SES it is important to consider both the social and ecological factors framing the context. Too much emphasis on economic poverty may be misleading as other aspects such as ecological can sometimes play a major role. In the results of this study, although the economic aspects are not entirely convincing to measure the intervention success, other social capacities and access to broader sets of assets were shown to be very strong. The results also show that using Kabeer's framework was appropriate because it allowed for consideration of multiple factors, as explained above.

\section{Critical factors toward sustainable transformations}

To understand the nature of poverty traps and the potential to foster transformations toward more resilient social-ecological systems, this study would benefit from being situated in the wider literature. The research field of "sustainability transformations" comprises several groups of resilience scholars (e.g., Gunderson et al. 1995, Olsson et al. 2006, Chapin et al. 2010, Folke et al. 2010, Westley et al. 2011). However, studies dealing with transformations in a marine context are few and when adding the link between existing literature and women's empowerment the number is remarkably low. Yet, Olsson et al. (2006) stress some critical factors of transformability that can be applied to this specific case. These include, among others, leadership functions (preparing the system for change, navigating the transition, and charting a new direction) as well as the need to have a long time horizon. In the Zanzibar-case, shell-handicraft as an innovative enterprise clearly had strong top-down elements, i.e., the intervention was external, not initiated by the women themselves, and instead introduced and driven by scientific institutions in Zanzibar Town, as well as international powerful actors such as USAID. In addition, the time scale of the development project was very short (a few years). To be able to thoroughly analyze the effect and assessment of the project it would benefit from a longer time horizon because restructuring of resilience cannot overlook slow dynamic processes. Moreover, although Olsson et al. (2014) argue that knowledge coming from outside is not necessarily a bad thing, they also stress that rather than forcing people to adapt 
to a solution, the solution should be adapted to the specific social, ecological, and cultural conditions of selected project areas (similarly to Haider 2017). Ideally, it should also make use of the internal community capacity, values, and resources found within (Berkes and Ross 2013). In this case, these factors were not thoroughly considered. It is noteworthy that Zanzibar, compared with, e.g., Latin America, South and West Africa, generally lacks strong (formal or informal) grassroots organizations in the marine/coastal context, which makes building on existing leadership, as well as knowledge and interaction across various actors (community members, authorities, and research institutes), networks, and scales, more challenging. This is likely one contributing factor to why the individuals involved do not have the capacity, or knowledge, needed to drive the changes further on their own. Subsequently, many challenges revealed, e.g., lack of tools and the means to solve the issue, problem of scaling up, limited market, do persist and may prevent the women, and the community at large, from fully transitioning into a more resilient state.

In terms of scale, a relatively low number of women from initially four small villages (Bweleo, Fumba Bondeni, Fumba Chaleni, and Nyamanzi) participated in the shell-handicraft project. Although the results found in this research are positive, the potential to spread the project to higher levels, e.g., the whole village, Zanzibar, Tanzania, and East Africa, is still absent and it is difficult to visualize how such a process can be promoted. The positive changes have been individual and not systemic. Although not the main objective of this project, it is advisable for future projects to address individual and household level dynamics together with wider community and political system dynamics to create robust change. One important concern worth mentioning is that the varying opportunity for project participation, and associated benefits, has also caused a feeling of injustice among Zanzibar people (Gustavsson et al. 2014).

Further, Boonstra and de Boer (2014) stress the importance of understanding and taking into account the historical role in the establishment of social-ecological traps to prevent future ones. Zanzibar, like many other low-income countries, has a long history of external donors initiating various development projects. However, good intentions may not necessarily translate into direct success stories. For example, in the early 1990s Zanzibar opened up for foreign investors, which added to competition over land and natural resources as a result of a thriving tourism industry. To alleviate poverty, and reduce the increasing pressure and conflict over resources, seaweed farming as a development project was introduced to coastal dwellers (mainly women) around the Island. However, when Fröcklin et al. (2012) analyzed the benefits versus the problems (20 years after its introduction) many problems associated with this top-down initiative were still present. For example, besides having potential negative effects on surrounding ecosystems, the women seaweed farmers also suffered from various health problems due to poor working conditions, low incomes, market fluctuations and most were trapped in a situation even worse than before. There are many differences between the seaweed industry, which is somewhat exploitative and driven by a global market, and shell-handicraft. Yet, one thing they have in common is the top-down element and general lack of capacity to navigate the transition and deal with the many challenges that arise along the way. Thus, learning from past interventions and understanding why and how such poverty traps developed and persisted, is crucial. Not only to avoid repeating the same mistakes, but to also identify potential barriers that must be addressed for successful interventions and long-term resilience of people, communities, and the environment on which they depend (e.g. Lade et al. 2017, Haider et al. 2018).

In sum, understanding the complex nature of interventions and poverty traps and how they arise and can be broken, requires a more integrated and thorough understanding of the interactions between social and environmental factors. Haider et al. (2018) propose four aspects that should help broaden the perspective of trap dynamics: (1) cross-scale interactions such as the issue of potential "mismatch between short-term economic gains and long-term wellbeing of people and the planet" or between "opportunities, desires, and abilities of the poor" (Haider et al. 2018:318), (2) path dependencies, e.g., poor initial conditions as a driver of traps, (3) the role of external drivers, e.g., historical legacies (Rudel et al. 2013) or external interventions enforcing rather than breaking traps (e.g., Banerjee and Chowdhury 2017), and (4) social-ecological diversity, addressing "the diversity of social-ecological linkages and the role diversity plays in adaptation and transformation out of undesirable states" (Haider et al. 2018:318). Drawing on existing theory and the above trap concept, the results from this study thus suggest that future innovations toward sustainable development should account for the following: (1) context-specific social, ecological, cultural conditions, (2) existing knowledge from within the community taking into account and including the women much more from the start, (3) history's role in the creation and recreation of traps to learn from past experiences, and (4) the need for strong leadership functions and networks to facilitate cross-learning and interaction among different actors at multiple scales. When absent, like in this case, emphasis should be put on building these elements. This should not only increase the sense of ownership, but also make the enterprise more resilient throughout the different transition phases. It should also make the intervention less dependent on external actors and their (sometimes) shortterm horizon.

\section{Future challenges}

One important issue that this research has not dealt with is the environmental aspects and effects of shell-handicraft. Torell et al. (2010) stated that linking livelihoods to resource management schemes, such as combining no-take zones, sustainable aquaculture, and shell-handicraft jewelry, or beekeeping with mangrove management, provides positive feedback loops, where successful enterprises, such as shell-handicraft, encourages conservation. However, this link between socioeconomic, environmental, and management factors in Zanzibar is largely understudied. But, it seems that more awareness on invertebrate overexploitation does exist. As a result of the SUCCESS project there are also local no-take areas managed by the women themselves and limiting sizes for the shell-fish collected, which is positive. However, little is known about potential undesirable behaviors promoted in the search for shells or in pearl cultivation, whether or not this enterprise interferes with food security and other uses of invertebrates, and if it has reduced the pressure on other coastal/marine resources. All these aspects require further research to fully understand and assess the social-ecological value of the shell-handicraft introduction. The management 
component is further very weak. Besides analyzing the ecological part of the system, women must be included in the processes of planning, decision making, and follow-up at community level. It has been previously shown that the invertebrate population declines can take place in short periods of time in Zanzibar. For example, Fröcklin et al. (2014) identified significant declines due to uncontrolled harvesting in a period of five years. In addition, there is a paucity of knowledge about species, links to their environment, and proper levels of up-take. It has been proposed that invertebrate harvesting can be better off if more ecological knowledge is acquired, time series and monitoring are implemented, and management includes all resource users, particularly women.

\section{CONCLUSIONS}

We show that women's empowerment, through the introduction of small-scale innovations such as shell-handicraft, is possible. The targeted women experienced improved access to financial, physical, human, and social resources, and decision making at individual level. Yet, there is still a long way to go at the household and community level. Unfortunately changes in income, although positive, were confounded by other livelihoods and thus require further research. Nevertheless, the case is an example of a good intervention attempt and provides valuable lessons for the future. To make more robust, scalable, and persistent transformation using these small-scale innovations, the process should include strong bottom-up elements and check for, and develop when absent, embedded leadership structures across scales. Piloting new livelihood activities plays an important role in planting seeds for the future. Yet, similar projects are recommended to take a broader approach and further be anchored in existing contextspecific socioeconomic, cultural, environmental, and management structures to contribute to long-term poverty alleviation and sustainable development. Finally, building resilience for the new regime has in this case been very fragmentary, and the shellhandicraft project could have been far better designed enabling conditions for continuity and delegating ownership to the local women.

Responses to this article can be read online at: http://www.ecologyandsociety.org/issues/responses. php/10136

\section{Acknowledgments:}

The authors thank all respondents for participating in this study, as well as Muumin Hamad for interpretation work and Bwana Dikos in the studied villages for field assistance. We further thank JanOlov Persson at Stockholm University for statistical consultancy. Appreciation to the Institute of Marine Science (IMS) in Zanzibar and the Department of Fisheries. This study has been financed by the Swedish Development Cooperation Agency (Sida) and the Swedish Research Council (Vetenskapsrådet, VR, diarenr. 344-2011-5448).

\section{LITERATURE CITED}

Banerjee, S., and A. N. Chowdhury. 2017. Globalisation of pesticide ingestion in suicides: an overview from a deltaic region of a middle-income nation, India. Pages 679-703 in R. G. White, S. Jain, D. M. R. Orr, and U. M. Read, editors. The Palgrave handbook of sociocultural perspectives on global mental health. Palgrave Macmillan, London, UK. http://dx.doi. org/10.1057/978-1-137-39510-8 32

Berkes, F., and H. Ross. 2014. Community resilience: toward an integrated approach. Society and Natural resources 26:5-20. http:// dx.doi.org/10.1080/08941920.2012.736605

Boonstra, W. J., and F. W. de Boer. 2014. The historical dynamics of social-ecological traps. Ambio 43:260-274. http://dx.doi. org/10.1007/s13280-013-0419-1

Chapin, F. S., III, S. R. Carpenter, G. P. Kofinas, C. Folke, N. Abel, W. C. Clark, P. Olsson, D. M. Stafford Smith, B. Walker, O. R. Young, F. Berkes, R. Biggs, J. M. Grove, R. L. Naylor, E. Pinkerton, W. Steffen, and F. J. Swanson. 2010. Ecosystem stewardship: sustainability strategies for a rapidly changing planet. Trends in Ecology and Evolution 25:241-249. http://dx.doi. org/10.1016/j.tree.2009.10.008 http://dx.doi.org/10.1016/j.tree.2009.10.008

Crawford, B., M. D. Herrera, N. Hernandez, C. R. Leclair, N. S. Jiddawi, S. Masumbuko, and M. Haws. 2010. Small scale fisheries management: lessons from cockle harvesters in Nicaragua and Tanzania. Coastal Management 38:195-215. http://dx.doi. org/10.1080/08920753.2010.483174

de la Torre-Castro. M., S. Fröcklin, S. Börjesson, J. Okupnik, and N. S. Jiddawi. 2017. Gender analysis for better coastal management: increasing our understanding of social-ecological seascapes. Marine Policy 83:62-74 http://dx.doi.org/10.1016/j. marpol.2017.05.015

Denscombe, M. 2007. The good research guide for small-scale social research projects. Third edition. Open University Press, Berkshire, UK.

Eklöf, J. S., M. de la Torre-Castro, C. Nilsson, and P. Rönnbäck. 2006. How do seaweed farms influence local fishery catches in a seagrass-dominated setting in Chwaka Bay, Zanzibar? Aquatic Living Resources 19:137-147. http://dx.doi.org/10.1051/alr:2006013

Eriksson, B. H., M. de la Torre-Castro, J. Eklöf, and N. S. Jiddawi. 2010. Resource degradation of the sea cucumber fishery in Zanzibar, Tanzania: a need for management reform. Aquatic Living Resources 23:387-398. http://dx.doi.org/10.1051/alr/2011002

Folke, C., R. Biggs, A. V. Norström, B. Reyers, and J. Rockström. 2016. Social-ecological resilience and biosphere-based sustainability science. Ecology and Society 21(3):41. http://dx.doi.org/10.5751/ ES-08748-210341

Folke, C., S. R. Carpenter, B. Walker, M. Scheffer, T. Chapin, and J. Rockström. 2010. Resilience thinking: integrating resilience, adaptability and transformability. Ecology and Society 15(4):20. http://dx.doi.org/10.5751/ES-03610-150420

Fröcklin, S. 2014. Women in the seascape: gender, livelihoods and management of coastal and marine resources in Zanzibar, East Africa. Dissertation. Stockholm University, Stockholm, Sweden.

Fröcklin, S., M. de la Torre-Castro, E. Håkansson, A. Carlsson, M. Magnusson, and N. S. Jiddawi. 2014. Towards improved management of tropical invertebrate fisheries: including time series and gender. PLoS ONE 9(3):e91161. http://dx.doi. org/10.1371/journal.pone.0091161 
Fröcklin, S., M. de la Torre-Castro, L. Lindström, and N. S. Jiddawi. 2013. Fish traders as key actors in fisheries: gender and adaptive management. Ambio 42(8):951-962. http://dx.doi. org/10.1007/s13280-013-0451-1

Fröcklin, S., M. de la Torre-Castro, L. Lindström, N. S. Jiddawi, and F. E. Msuya. 2012. Seaweed mariculture as a development project in Zanzibar, East Africa: a price too high to pay? Aquaculture 356-357:30-39. http://dx.doi.org/10.1016/j. aquaculture.2012.05.039

Gunderson, L. H., C. S. Holling, and S. S. Light, editors. 1995. Barriers and bridges to renewal of ecosystems and institutions. Columbia University Press, New York, New York, USA.

Gustavsson, M., L. Lindström, N. S. Jiddawi, and M. de la TorreCastro. 2014. Procedural and distributive justice in a communitybased managed marine protected area in Zanzibar, Tanzania. Marine Policy 46:91-100. http://dx.doi.org/10.1016/j.marpol.2014.01.005

Haider, L. J. 2017. Development and resilience. Re-thinking poverty and intervention in biocultural landscapes. Dissertation. Stockholm Resilience Center, Stockholm University, Sweden.

Haider, L. J., W. J. Boonstra, G. D. Peterson, and M. Schlüter. 2018. Traps and sustainable development in rural areas: a review. World Development 101:311-321. http://dx.doi.org/10.1016/j. worlddev.2017.05.038

Jiddawi, N. S., and M. C. Öhman. 2002. Marine fisheries in Tanzania. Ambio 31:518-527. http://dx.doi.org/10.1579/0044-74$\underline{47-31.7 .518}$

Kabeer, N. 1995. Reversed realities: gender hierarchies in development thought. Verso, London, UK.

Kabeer, N. 1999. Resources, agency, achievements: reflections on the measurement of women's empowerment. Development and Change 30:435-64. http://dx.doi.org/10.1111/1467-7660.00125

Kabeer, N. 2005. Gender equality and women's empowerment: a critical analysis of the third Millennium Development Goal. Gender and Development 13:13-24. http://dx.doi. org/10.1080/13552070512331332273

Kvale, S. 1994. An introduction to qualitative research interviewing. Studentlitteratur, Lund, Sweden.

Lade, S. J., L. J. Haider, G. Engström, and M. Schlüter. 2017. Resilience offers escape from trapped thinking on poverty alleviation. Science Advances 3:e1603043. http://dx.doi. org/10.1126/sciadv. 1603043

Lange, G.-M. 2015. Tourism in Zanzibar: incentives for sustainable management of the coastal environment. Ecosystem Services 11:5-11. http://dx.doi.org/10.1016/j.ecoser.2014.11.009

Nordlund, L., J. Erlandsson, M. de la Torre-Castro, and N. Jiddawi. 2010. Changes in an East African social-ecological system: invertebrate harvesting affecting species composition and local livelihood. Aquatic Living Resources 23:399-416. http://dx. doi.org/10.1051/alr/2011006

Olsson, P., V. Galaz, and W. J. Boonstra. 2014. Sustainability transformations: a resilience perspective. Ecology and Society 19 (4):1. http://dx.doi.org/10.5751/ES-06799-190401
Olsson, P., L. H. Gunderson, S. R. Carpenter, P. Ryan, L. Lebel, C. Folke, and C. S. Holling. 2006. Shooting the rapids: navigating transitions to adaptive governance of social-ecological systems. Ecology and Society 11(1):18. http://dx.doi.org/10.5751/ ES-01595-110118

Rudel, T. K., T. Katan, and B. Horowitz. 2013. Amerindian livelihoods, outside interventions, and poverty traps in the Ecuadorian Amazon. Rural Sociology 78 (2):167-185. http://dx. doi.org/10.1111/ruso.12009

Torell, E., B. Crawford, D. Kotowitcz, M. D. Herrera, and J. Tobey. 2010. Moderating our expectations on livelihoods in ICM: experiences from Thailand, Nicaragua, and Tanzania. Coastal Management 38:216-237. http://dx.doi.org/10.1080/08920753.2010.483166

Westley, F., P. Olsson, C. Folke, T. Homer-Dixon, H. Vredenburg, D. Loorbach, J. Thompson, M. Nilsson, E. Lambin, J. Sendzimir, B. Banarjee, V. Galaz, and S. van der Leeuw. 2011. Tipping toward sustainability: emerging pathways of transformation. Ambio 40:762-780. http://dx.doi.org/10.1007/s13280-011-0186-9

World Population Review. 2018. Tanzania population 2018. [online] URL: http://worldpopulationreview.com/countries/ tanzania-population/ 